\title{
THE PROPOSAL TO TAX SMALL INCOMES ${ }^{2}$
}

\author{
PaUl J. Strayer
}

The proposal to tax small incomes is a recent development. The suggestion that the personal exemptions of the federal income tax should be lowered has been favored by groups with aims diametrically opposed. One group would like to see the exemptions lowered for the purpose of increasing the total revenue of the federal governmenc. Anuther group favoring retrenchment believes that the lowering of the exemptions will result in an increase in tax consciousness and a growth of popular strength in an expenditure reduction program. The third group favors the reduction primarily as a means of improving the distribution of the tax burden in the lower brackets. It is believed that this can be done if the income tax is used in place of some of the existing taxes bearing heavily on the poor or resulting in unequal treatment of persons in the lower brackets.

It is clear that any measure that receives the support of such different groups is an attractive means of improving the tax system. However, there is little evidence bearing directly on the effectiveness of the suggested remedy. It is the purpose of this paper to supply the missing data. First, there is the problem of the total amount of revenue that may be obtained. Second, one must consider the distribution of the existing tax burden and the possibility of.improving it. Third, is the question of tax consciousness; how it may be generated, and its possible effects. Fourth, and of at least as much importance as any of the other points, is the question of the administrative practicability of the direct taxation of small incomes. It is of interest to note that it is on this important issue that there has been the least thought.

\section{Revenue Aspects}

Some idea of the yield of the tax on small incomes is necessary, if there is to be a decision as to the merit of the current proposal. It is difficult to-make estimates of an exact nature. The yield will vary as the tax rate imposed is high or low, and with the decision as to the desirable level of exemption. Another source of variation is the size and the distribution of the national income. The fluctuations from a good

A .B, 1933, Skzrthmore College; M.A., 1935, Ph.D, 1939, Columbia University. Instruetor in Economics, Princeton University. Assisted, as a member of the Twenticth Century Fund resesch staff in 1936, in the preparzion of the study, Facisc trie Tax Paoblem, Carl Shoup, Director, New York, 1937. Author of THE TAsation of SMare. Incomes (Ronald Press, New York, 1939) and contributor to tax periodicals.

1 This article is based on Tre Taxanow of Suarl Incoves (1939) by the same author. As most points are dereloped more fully in the book, no specific reference to it will be made. 
year to a year of depression make a single estimate of little value. There is also the problem of evasion. Data on this point can be obtained only by actual trial under existing conditions. However, by making assumptions as to the rates, level of exemption, and year, it is possible to set the maximum that might be expected to be gained from the tax on small incomes.

Senator $\mathrm{La}$ Follette has proposed that the exemption of the present income tax be lowered from $\$ 2,500$ for married persons or heads of a family and $\$ 1,000$ for single persons to $\$ 2,000$ for married persons and $\$ 800$ for the single person. He suggests that the $\$ 400$ dependent allowance remain unchanged with the proviso that all children receiving family support be included in this categury up to the age of twenty years, rather than eighteen. If a normal rate of $4 \%$ were maintained, the Treasury estimates such a reduction in exemptions would yield an additional $\$ 60,400,000$ on 1938 incomes. ${ }^{1}$ A later estimate for the calendar year 1939 places the increase in the yield at $\$ 56,400,000 .^{2}$ If the same exemptions as proposed by La Follette were to be used with a normal tax rate of $5 \%$, instead of the usual $4 \%$, the estimate for the calendar year 1939 would be increased to $\$ 135,600,0000^{3}$

Other estimates are available for a lower level of exemption and a normal rate of $4 \%$. These estimates prepared by the Twentieth Century Fund are presented in Table I below.

Table I. Estimated Yield of Personal Income Tax with Various

LEVELS OF EXEMTtTONS*

\begin{tabular}{|c|c|c|c|c|c|c|}
\hline & \multicolumn{2}{|c|}{1928 Incomes. } & \multicolumn{2}{|c|}{ r933 Incomes } & \multicolumn{2}{|c|}{1934 Ineomes } \\
\hline $\begin{array}{l}\text { Exemptions: } \\
\text { Married........... } \\
\text { Single........... } \\
\text { Dependent........ }\end{array}$ & $\begin{array}{r}\$ 2,500 \\
1,000 \\
400\end{array}$ & $\begin{array}{r}\$ 1,000 \\
500 \\
200 \\
\end{array}$ & $\begin{array}{r}\$ 2,500 \\
1,000 \\
400\end{array}$ & $\begin{array}{r}\$ 1,000 \\
500 \\
200\end{array}$ & $\begin{array}{r}\$ 2,500 \\
1,000 \\
400\end{array}$ & $\begin{array}{r}\$ 1,000 \\
500 \\
200\end{array}$ \\
\hline $\begin{array}{c}\text { Normal tax at } 4 \%^{2} \ldots . \\
\text { Surtax: } 1936 \text { Act...... } \\
\text { Total Tax.......... } \\
\text { Gain in normal tax.. } \\
\text { Gain. in surtax...... } \\
\text { Total gain......... }\end{array}$ & $\begin{array}{r}\quad \text { Yic } \\
432 \\
2,474 \\
2,907 \\
\\
\quad 39 \\
100 \\
49\end{array}$ & $\begin{array}{l}\text { eld in mi } \\
826 \\
2,574 \\
3,401 \\
4 \\
4\end{array}$ & $\begin{array}{c}\text { dollars) } \\
105 \\
379 \\
483\end{array}$ & $\begin{array}{l}282 \\
407 \\
689\end{array}$ & $\begin{array}{r}121 \\
413 \\
533 \\
2 \\
2\end{array}$ & $\begin{array}{l}334 \\
454 \\
788\end{array}$ \\
\hline
\end{tabular}

- Source: Shoup and Others, Facing taie Tax Problex (Twentieth Century Fund, Inc., 1937), table 7, pp. 74-75.

- Dividends assumed exempt from normal tax. With this exception the net income subject to normal tax and surtax is as defined by the Revenue Act of 1936.

The level of exemption used in these estimates is probably as low as would be suggested by the most ardent advocate of the tax on small incomes. The use of 1928

183 CoNG. REc. 5162,5163 (1938).

Hearings before the Committee on Ways and Means on Revenue Revision 8939, 76th Cong., 1st Sess. (1939) 182.

Ibid. 
incomes provides an estimate of the yield of the tax under the unusually favorable conditions. The estimates based on the incomes received in 1933 and 1934 give some idea of the extent to which the tax might be expected to fall off in the depths of a depression. The increase in the income tax yield of $\$ 494$ millions for the income year 1928 might be thought of as the maximum and the $\$ 205$ millions increase in the income year 1933 as the maximum additional revenue at the suggested exemption level. These estimates assume that the administration would stand up under the strain. This is not certain.

It is obvious that even under the most favorable conditions there is little possibility of achieving a balanced budget by lowering exemptions. The amounts involved are sufficiently large, however, to be of significance and would permit modification of the federal tax structure. For example, the increase in revenue in the year 198 would have permitted the replacement of the federal tobacco taxes, automotive taxes, admissions tax and capital stock transfer tax. The estimated increase in 1933 would have been sufficient to offset approximately half the federal tobacco taxes for that year.

These cstimates may be misleading to one unfamiliar with income tax procedure. This is because the increase in yield is the result of additional contributions. from existing taxpayers as well as from persons who had never paid an income tax before. The present system grants the personal exemption to all taxpayers regardless of the size of the income. Thus, a married couple without any children, who earn $\$ 3,000$, will pay a $4 \% \operatorname{tax}$ on $\$ 200$. If their exemption is lowered to $\$ 1,000$ and their net income remains the same, they will pay a $4 \% \operatorname{tax}$ on $\$ 1,700$. It is clear that the lowering of the exemption level will bring in a considerable amount of new revenue from persons-already subject to the income tax. It is diffcult to estimate the net contribution of new taxpayers to the totals given above. However, it is probably safe to say that it is not over $60 \%$ in the case of the Twentieth Century Fund figures. This suggests two points. One, is that a large part of the increased revenue obtained from the lowering of the exemption levels might be obtained by the raising of the rates on existing income taxpayers. The other is that it would be desirable to change the form of the exemption to a deduction in terms of tax. This has been done by several of the states and has the advantage of giving everyone an exemption of equal value and also the advantage of making it possible to estimate with ease the exact amount contributed by new taxpayers, should the exemptions be lowered by the federal government.

It is a common belief that, if it is necessary to raise a lot of money, the best source is to be found in the mass of the population with the low incomes. The success of the state sales tax, the British tea duty, and the federal excises on tobacco and liquor support this view. However, the estimates presented above do not indicate that the lowering of the personal income tax exemptions will lead to a very large increase in income tax revenue. There are several reasons for this lack of pro-

-The earned income allowance increases the tar-free income by $10 \%$. 
ductivity. First, the suggested exemptions are still sufficiently high to leave the larger part of the population free of tax. Secondly, the tax on these incomes would be assessed on only that portion of the income above the exemption in contrast to the sales tax which is assessed on all purchases without any exemption. Lastly, there is the fact that the distribution of the national income is such that the poorest half of the population receives much less than half the national income. The Brookings Institution estimates that in $1929,64.8 \%$ of all personal incomes were $\$ 1,500$ or less, and that the aggregate of all these incomes was only $28.8 \%$ of the total national income for that year. ${ }^{5}$ On the other hand, they estimate that in the same year $1.8 \%$ of all personal incomes were $\$ 8,000$ or more, and that the aggregate of these incomes was $27.9 \%$ of the total national income. The estimates of the National Resources Committee for $1935-36$ indicate that "the highest five per cent of all families and single individuals - those with incomes of $\$ 3,401$ ) and over-received 27 per cent of the aggregate-almost as much as the lowest 60 per cent."

The effect of the concentration of the national income in the top brackets and the use of the progressive rate scale is well illustrated by the aralysis of the federal income tax statistics for 1936 . In that year, the returns of over $\$ 5,000$ were $12.51 \%$ of the total, but were the source of $92.02 \%$ of the total revenue. As long as this condition prevails, there is no chance that the lowering of the exemptions will prove to be a source of funds as important as the raising of the rates in the middle and upper brackets.

Although the additional revenue obtainable from the lower bracket income tax is not large, as sometimes believed, some of the advocates of lower exemptions suggest thai the yield of the income tax would be stabilized if the exemption limit were lower. Inspection of Table I, above, does not support this belief. Although the decline in the yield of the personal income tax from 1928 to 1933 is slightly less on a percentage basis, the absolute decline is much greater with lower exemptions. The concentration of income in the high brackets, and the fact that these incomes are subject to the highly progressive rates, seem to be the main reasons for the variation in yield. The inclusion of capital gains in the definition of taxable income also tends to increase the variability of the yield. Although the greater stability of the British income tax is often attributed to the low exemptions, it can be much more readily explained by the fact that the British law does not include capital gains, the maximum rates are not as high and are reached more rapidly than under the United States law, and, most importantly, the fact that the national income in Great Britain has not been nearly as variable as in the United States.

It may be concluded that the revenue potentialities of the tax on small income are attractive but do not support the belief often expressed, that this is a solution to the problem of declining income tax returns in depression.

- Leven, Moulton, and Warburton, America's Capacity to Consume (1934) 207.

- Nat. Resources Committee, Consumer Incomes in the United States (1938) 6. 


\section{Exemption Theory}

If the exemptions of the personal income tax are to be lowered, the question arises as to what extent and with what justification. Since the first modern income tax was passed in England in 1799 , there has been some minimum income level below which the tax would not apply. This minimum has varied from time to time. The Revenue Act of Igr 3 granted an exemption to married persons with income of less than $\$ 4,000$ and single persons with incomes of less than $\$ 3,000$. At the present time a mere subsistence is granted in Germany. The only consistency in the exemption policy of the different governments is that at least some amount is completely froe from income tax.

The most common justification of the exemption of some minimum income is that it is not just or economically wise to tax incomes below the level of subsisterce. This has been expanded by some later writers to include not only a bare minimum but also some additional amount necessary for the maximum efficiency of the worker. There are two objecions to this theory of the exemption policy. In the first place, there is no agreement as to the specific sum to be left trix-free. In the second place, most of those who favor the subsistence argument do not rake into account the fact that the same government that provides for exemption from the income tax collects a large part of its revenue by means of various excises and indirect levies passed on to the general consumer at all income levels.

A more realistic explanation of the exemption policy must take into account the burdens imposed by other taxes of the system. If this is done, it becomes clear shat the exemption from income tax must be justified on other grounds. From the political and administrative points of view the desire to "pluck the goose with the least squawking" is an important consideration. The income cax might cause a great deal more opposition to an administration than some other means of raising the same amount of revenue. A tax that can be paid in small sums over the whole year is probably less irritating than the income tax. If the litele fellow pays his tax in the form of higher prices for the goods he buys, the practical politician is even better pleased, at least until someone stirs up the mass of the voters to realize that they are taxpayers. If indirect caxes are used, there is obviously little justification for the imposition of an additional income tax on the person in the lowest brackets.

One additional factor must be included in the explanation of the practical policy followed by different governmenes. Regardless of the other taxes imposed, the tendency has been for the level of personal income tax exemption to vary, as there is need for more or less total revenue. No better example neel be cited than that of the lowering of the federal income tax exemption from $\$ 4,000$ to $\$ 2,000$ for married persons between 1913 and 1917 and the subsequent raising of the level to $\$ 3,500$ in 1926 .

It is apparent that no one theory of exemption will serve as a basis for policy. No single tax may be considered good or bad unless its place in the tax system is 
realized. The case for the lowering of the present federal exemptions must, therefore, be considered in light of other federal levies. Two possibilities are presented: First, the lowering of exemptions without other modification of the tax system. Second, the possibility of improving the present distribution of the tax burden by the substitution of the lower bracket income tax for some other less desirable measure.

\section{The Distribution of the Federal Tax Burden}

Any decision as to the desirability of either of the alternatives suggested above will depend upon the individual bias as to the desirable: distribution of the total federal tax burden. This is a matter where there is little basis for an appeal to anything but the most general guides provided by writers in the field. Seligman has advanced the theory thac the tax burden should be distributed on the basis of faculty, differing only slightly from the more generally accepted theory of rasation according to ability. To give exact meaning to these concepts is obviously impossible. The questions involved are primarily ethical and of the nature of all questions of right or wrong, based on some concept of the most desirable form of social relationships. Effects on economic productivity are to be included, but they are of no greater importance than the social consequences. In the limits of this paper it is impossible to give the basis for any one theory of the ideal distribution of the total burden. However, it will be assumed that the present state of economic and political opinion favors the maintenance of a progressive distribution of the federal tax burden. The use of progressive rates under the personal income tax gives support to this vievr. It will also be assumed that net income is the best base for the measurement of taxable capacity. This is with the exceptions of special regulatory taxes and ochers to be justified on the basis of benefit or cost of service. Adjustments in taxable income to allow for the differences in ability, such as the allowance for dependents, are also believed to be desirable.

There is general agreement that, for the purpose of general revenue, the burden of taxation shculd rest equally on persons with similar incomes and responsibilities. The desirability of relieving the lowest income groups from any contribution to the support of their government is not so acceptable. This is not the practice at the present time. The burden imposed by the various indirect levies is generally believed to be shifted, at least in part, to all purchasers of the recessines of life. Many persons favor-at least a token payment in recognition of the obligation of all citizens to contribute to the support of their government. However, there is general agreement that the total to be collected from those with less than an adequate subsistence income should not be forced to make a large contribution. This is bolstered by the fact that this group is the recipient of a good part of the social service outlays of the federal government and there would be little point in the collection of sums that would be immediately paid back to those same persons in increasing measure.

With this set of aims the desirability of a lower level of personal exemptions may 
be more realistically considered. First, there is the question of the progressivity of the federal tax structure. There seems to be little doubt that the progressive income tax rates provide the progression from the $\$ 5,000$ level up. Not only the income tax but the estate and gift taxes become effective at this level. This group is, however, a very small part of the total tax-paying population. At present, the largest number of income taxpayers would not be expected to increase to more than four or five millions. Assuming that each taxpayer represent a family group, the maximum number of families affected is probably about one-sixth of the total in the country. The mass of the population contributes to the federal government only indirectly as the result of the federal excise, tariff, and social security taxes. The tobacco and liquor taxes are the largest revenue producers of this group. The social security taxes are not general levies and customs revenue is only an indirect objective of the present tariff schedules. These taxes are levied at proportionate rates and affect the taxpayer by increasing the cost of the goods he buys. As expenditure of income for the items taxed is generally less as the size of the income increases, there is little doubt that the result is a regressive distribution of the federal tax burden in the lower brackets. That is, the percentage tax contribution of those in the lowest income brackets is larger than those in the higher income brackets.

The second major requirement is that the tax burden should rest equally on persons with similar incomes and responsibilities. This is based on the assumption that persons with equal money incomes enjoy equal satisfactions and that some monetary allowance may be made for differences in responsibilities. This is probably not true in all cases but appears to be a more reasonable assumption than any alternative that presents itself.

Excluded from consideration are taxes that may be justified on the basis of benefits received. Of the federal taxes this will exclude the gasoline tax and the social security taxes. As indicated above, the important sources of revenue in the lower brackets are the tobacco and liquor taxes and the federal excise taxes. It is obvious that unless similar amounts of the commodities taxed are consumed by taxpayers in similar positions, the requirement of equality will not be fulfilled, as the burden imposed is in proportion to the volume of consumption. This is not true. The few commodities taxed makes the possibility of discrimination even greater for the federal taxpayer than it would be for the person paying the state sales tax. For example, a non-smoker will avcid all the tobacco tax. The justification of this discrimination on moral grounds seems rather far-fetched at the present time.

The allowance for differing responsibilities is also impossible to satisfy with the use of the indirect tax. As a matter of fact, as responsibilities increase, the portion of the income spent on taxed commodities is likely to increase. Thus, the tax burden will be greater for the person with the large family than with the small. Some adjustment might be made by the imposition of excises on luxury goods. This might seem an attractive way to make the desired allowance but would be either an unimportant source of revenue or would still permit considerable discrimination. 
The commodity that is a luxury to one family in the lower brackets may be a necessity. to another.

Finally, the question of the desirability of relieving a part of the burden on families with incomes below a subsistence level requires attention. Whether the objective is the complete exemption of this group, or the restriction of the tax to a nominal contribution, the use of the indirect tax on widely purchased commodities will prevent its attainment. Not only is it impossible to relieve this group from a substantial contribution to the federal government but the existing uncertainty as to the amount of the indirect taxes that may be shifted makes the exact burden a matter of conjecture. It seems clear that the attainment of either objective will be impossible under the present federal tax system.

On the basis of the evidence presented above, the present distribution of the tax burden falls short of the ideal. It is clear that it is necessary to look to some other means of raising revenue if it is to be attained. The personal income tax seems'to be the most attractive alternative. Assuming that it is administratively possible to substitute the personal income tax for the present indirect levies on the lower bracket incomes, there is no question that a much closer conformity to the ideal distribution of the tax burden might be attained. Under the personal income tax, rates may be adjusted to assure any degree of progression desired. As it is generally agreed that there is no shifting of the income tax burden there would be no problem of the unequal taxation of persons with similar incomes. Allowance for individual differences in capacity arising out of other factors than income can be made. The granting of complete exemption to the lowest income group may be assured if indirect levies are replaced by an income tax with exemptions of the desired level. If some token payment is desired to indicate the obligation of all citizens to their government this could be accomplished by the imposition of some minimum fee for all persons regardless of the size of their income.

The advantages of the income tax as a means of attaining the ideal distribution of the tax burden are not restricted to the ideal as outlined above. Most any type of program can be more certainly realized by the use of the income tax with its certain incidence of the tax burden. The one exception is the possibility of the distribution of the tax burden on the basis of benefits received or cost of service. This may be attained with some other type of tax. However, it is not likely that general agreement as to the desirability of the distribution of the general tax burden on the basis of ability will change in the near future.

\section{Tax Consciousness}

A most appealing case for the proposal to tax small incomes has been made on the basis that it would generate increased tax consciousness. In many cases this has been the primary argument advanced in favor of the proposal. Tax consciousness is not usually desired as an end in itself but as a means to attain some further objective. One of the most common beliefs is that an increase in tax consciousness 
will develop a sense of political responsibility and prevent the masses from favoring excessive expenditures with the belief that they will be able to pass the burden to the wealthy. Although the argument is sometimes stated in general political terms, more often the creation of tax-conscious voters is favored as a means of achieving a specific political objective. The most frequent objective is the control or reduction in the size of the federal expenditure. It is also suggested that greater tax consciousness might prevent military expenditures leading to participation in a war. Another reason for the advocacy of lower exemptions is the belief that high-bracket taxpayers realizing the burden imposed upon the mass of the population would be more willing to pay their high rates than they are at the present time.

The desirability of lower exemption to increase tax consciousness is dependent upon the assumption that the present tax system does not create tax-conscious citizens in the lower brackets. This assumption seems to be fair with respect to the federal government. The only tax collected directly from the lower income brackets is the social security tax. Although a large per cent of the population is required to make this payment for old-age pensions, it is of less importance than it might be because it is directly connected in the taxpayer's mind with his eligibility for the old-agepension. It is also subject to the disadvantage of being collected at the source as a regular deduction from wages and may in time be accepted as a matter of course. Other taxes that impose a burden on the small income recipient are not assessed in a manner calculated to generate much tax consciousness. The only one that might have some effect is the tobacco tax. However, it is not likely that the average smoker is aware of the fact that the internal revenue stamp on each package of twenty cigarettes is an indication of his contribution to the federal treasury.

Even if it is concluded that the income tax is a desirable means of increasing the degree of tax consciousness it is not certain that this will be the result. If the income tax were to be collected at the source, there would probably be less tax consciousness than if it were paid directly. If the amount does not vary with the size of the federal expenditures there will be less appreciation of the trend of fiscal policy than if the rate is allowed to vary with the revenue needs of the government. A flat fee is therefore less desirable than a varying rate. If it is believed to be desirable for administrative or distributive reasons to provide for some minimum exemption, this will also work against tax consciousness in the lowest brackets. However, there is little question that the lower the exemptions under the federal income tax, the greater the number of citizens who will be made directly aware of the cost of the federal government.

It has been assumed up to this point that the creation of tax-conscious citizens is desirable or that it will accomplish the aims set forth by those who wish to see it increased. The evidence does not indicate that this is certain. The reaction of the taxpayer is unpredictable and may result in greater rather than less expenditure. Another possibility is that if the mass of the voters were to be made tax-conscious they would demand the repeal of the tax. This was the experience of New Jersey, 
when it imposed a sales tax. Indiscriminate creation of tax consciousness may have other adverse results. Special groups may use it to further their own narrow interests. It is also true that all expenditure reductions are not desirable. Examples of diffculties of this sort are found in the constitutional property tax rate limits, homestead exemptions and in the tendency for unwise curtailment of public expenditure for such services as public education.

There is no positive evidence that the creation of tax consciousness will have a generally beneficial effect. Interviews with officials in the British administration indicate that their low exemptions are not of much practical significance except as they make the persons in the higher brackets feel better about their heavy burdens. An indication of the British attitude is found in the fact that recent increases in the tax burden were effected by increasing the income tax rates in the middle and upper income brackets and an increase in the tea duty by two pence a pound to collect more from the lower brackets.

It may be concluded that the argument in favor of the income tax at lower levels is not materially strengthened by its possible effects on tax consciousness. If reform is desired, a better way to attain it would be to educate the taxpayers in such a way that they will be able to make intelligent choice among alternative policies on the - basis of complete knowledge rather than as a result of the irritation resulting from the imposition of some particular levy.

\section{Administrative Aspects}

Before any conclusions. may be reached as to the desirability of the proposal to tax small incomes, the administrative practicability of such a tax must be investigated. First, there is the question of the feasibility of any such tax. In the second place, the type of tax administration that seems to be possible will have important bearing on its advantages as a substitute for existing levies on the poorer classes.

If the advantages claimed for the personal income tax are to be realized, there is little hope for a simple tax. It might be conceded at the start that the personal income tax is more difficult to administer than many alternative levies. If allowance is to be made for every slight difference in ability, the extreme of a tax assessed on a completely individual basis might be the result. However, even if some compromise is made for the practical limitations the maintenance of the desirable features of the personal income tax will present complex problems. These are accentuated in the lower brackets by the fact that the data are less certain and the numbers of taxpayers are increased many times.

The most certain advantage of the income tax is that it is the most equitable means of collecting revenue for general purposes. It is not certain, however, that this advantage can be maintained if the level of exemption is lowered. In the first place, additional difficulty is to be anticipated in the determination of the net taxable income. Allowance for expenses necessary to the acquisition of income would probably have to be made on the basis of occupation rather than individually. This has been the experience in Great Britain but has worked to the satisfaction of all con- 
cerned. In any event, the fact that some allowance is made is a point in favor of the income tax. An additional source of diffculty is found in the fact that in the lower brackets equality would demand some recognition of the fact that money income is not the only source of real income. The farmer will often enjoy a large part of his income in the form of produce. It is difficult to measure the value of such income. As this type of income is more important in the lower brackets, failure to recognize it might lead to serious complaint. However, as no recognition of this factor is made under the present tax system, failure to allow for it under the income tax would not be a serious argument against the proposed change.

A more serious limitation of the tax on small income is found in the difficulty of measuring accurately the total cash income of wage-earners, farmers, and-others in the lower brackets, who keep poor records and may not know what their total income amounts to. Deduction of the tax at the source would help in the case of industrial workers, but would not help in the case of the farmer or the small business man. The present exemption of this group from the social security taxes is justified on the basis of administrative limitations. It is possible that inequitable assessments might lead to extensive evasion and the break-down of the income tax program.

It is also clear that the payment of the tax by the lower income groups would have to be in small amounts at frequent intervals. A weekly wage-earner thinks and acts on the basis of the week, rather than the year. How much additional difficulty this might create is not certain, but it is another factor tending to complicate the administration.

If it is assumed that the lower-bracket income tax will meet the requirements of equity, there is still to be considered the cost of the administration of such a tax. If a large part of the tax collected is required to pay for its administration, there is little advantage in the attainment of additional equity. Unfortunately there is little evidence on this subject. It is believed, however, that cost of collection would be increased by the lowering of the exemption level. An indication of the possibilities is found in the experience of Utah. A personal income tax adopted by that state in 1931 required the filing of a return with a fee of one dollar by all citizens unless "infirm, idiotic, insane or indigent." Rates of the general income tax were low and the offset of property tax up to one-third of the net income was permitted. In spite of these additional factors leading to high administrative costs, the fact that in 1933 . $34 \%$ of the tax collected was required for administration gives some indication of the nature of the problem. The state tax commission recommended the repeal of the fee. When this was done, costs were reduced to a normal level.

The experience in Great Britain tends to support the conclusion that the income tax is very expensive to collect in the lower brackets. Although there are no authoritative data available the most recent estimate made by Mr. Churchill placed the cost of collection of the income tax on weekly wage earners at $33 \%$ of the yield in I928. Members of the British administration have recently informed the writer that there 
are. no statistics available to indicate the exact costs involved. However, they gave the impression that the costs were large in proportion to the revenue collected from the lower brackets.

Various means of administering the income tax in the lower brackets may be considered with the possibility of reducing the cost of collection and preventing evasion. One of the most attractive suggestions is that the tax might be collocted at the source. Although this would not help in the case of the farmer, or small business man, it is possible that the industrial worker could be assessed more easily by some such device. There is one danger. This is, that the difficulties of administering even this type of tax would lead to its modification and the cventual adoption of a gross income tax or wage tax with no allowance for unemployment or differing responsibilities. Thus, the gain in equity would be less than anticipated in the original tax bill.

It may be concluded that the administrative difficulties of the taxation of small incomes are serious. Prudence would suggest that any immediate change be undertaken. slowly and that care should be exercised in the maintenance of records to indicate the success of the experiment. The problem of administrative organization and personnel requires serious attention. The successful British administration can be studied with profit. The more recent developments in the Australian states are also of interest to anyone responsible for the development of an administrative organization to cope with the problem. However, in the last analysis the solution of the American problem will have to be worked out in our own way. Special problems arise out of the diversity of our economy. Varying economic conditions in different areas would seem to prevent the adoption of a single administrative program. $\mathbf{A}$ successful modification of the present tax system cannot be accomplished overnight and should be based on extensive investigation of all the possibilities. 